\title{
Lymphoma-like presentation of acute monocytic leukaemia
}

\author{
BARBARA BAIN, * A MANOHARAN, $\dagger$ I LAMPERT, $\ddagger$ C McKENZIE,§ D CATOVSKY $\dagger$ \\ From the *Department of Haematology, St Mary's Hospital Medical School, London and the $†$ MRC \\ Leukaemia Unit and Departments of $\ddagger$ Histopathology and $§$ Radiotherapy, Royal Postgraduate Medical \\ School, London.
}

SUMMARY Four patients in whom a diagnosis of acute monocytic leukaemia (M5) was subsequently made presented with extramedullary disease clinically resembling lymphoma. In all patients histological sections were initially misinterpreted as showing malignant lymphoma or anaplastic carcinoma. The diagnosis of M5 leukaemia was subsequently made on the basis of morphological and cytochemical studies of peripheral blood and bone marrow. The histological diagnosis of the soft tissue lesions of M5 leukaemia (monocytic sarcoma) is difficult, although features such as abundant cytoplasm and the presence of some reniform nuclei are helpful. If there is no peripheral blood or bone marrow involvement and only fixed paraffin-embedded tissues are available, demonstration of lysozyme by an immunoperoxidase technique may confirm the diagnosis but results are not invariably positive. An early diagnosis of M5 leukaemia has therapeutic implications since the disease evolves through a progressive leukaemia phase and systemic therapy is essential.

The majority of patients with acute monocytic leukaemia present with clinical features consequent on bone marrow occupation by leukaemic cells. Many also show features resulting from leukaemic infiltration of the liver, spleen, lymph nodes, skin, and gums. A minority of patients present with soft tissue tumour formation with little or rarely no evidence of bone marrow disease. In such patients misdiagnosis of tumours composed of leukaemic monoblasts or monocytes (monocytic sarcoma) as lymphoma or carcinoma appears to be common. The recognition of the true nature of these tumours is important in relation to both prognosis and appropriate treatment. We have observed four patients in whom histological sections from a monocytic sarcoma were misdiagnosed as lymphoma or carcinoma.

\section{Case reports}

CASE 1

A 55-year-old man presented with a two-month history of tumour formation between the eyes and in the right nostril. In addition he had massive cervical lymphadenopathy and extensive infiltration of the skin of the face and trunk. Biopsy specimens were

Accepted for publication 8 December 1982 first interpreted as undifferentiated carcinoma and subsequently as diffuse histiocytic lymphoma. ${ }^{1}$ The blood count was normal and a bone marrow aspirate was not done. The forehead lesion was irradiated and cyclophosphamide and vincristine were given. Two months after presentation (seven months from first symptoms) the white cell and platelet counts had fallen; monoblasts and promonocytes were present in the peripheral blood (Fig. 1, Table) and constituted $80 \%$ of bone marrow cells. The morphology was that of acute monocytic leukaemia (M5PD in the FAB classification ${ }^{3}$ ). There was no response to combination chemotherapy and the patient died 10 days later. Necropsy examination showed extensive leukaemic infiltration of many organs, including the testes.

\section{CASE 2}

A 17-year-old man presented with generalised pruritis and a five-month history of a lump in the right side of the neck. He was found to have marked right cervical and bilateral axillary and inguinal lymphadenopathy. Significant features of the peripheral blood count were Hb $13.3 \mathrm{~g} / \mathrm{dl}$; WCC $2.4 \times 10^{2} / 1$; neutrophil count $1.0 \times 10^{9} / 1$; monocyte count 0.26 $\times: 10 \% / 1$; platelet count $249 \times 10^{9} / 1$. Several atypical mononuclear cells were seen and the bone marrow aspirate showed small foci of "primitive cells" prob- 


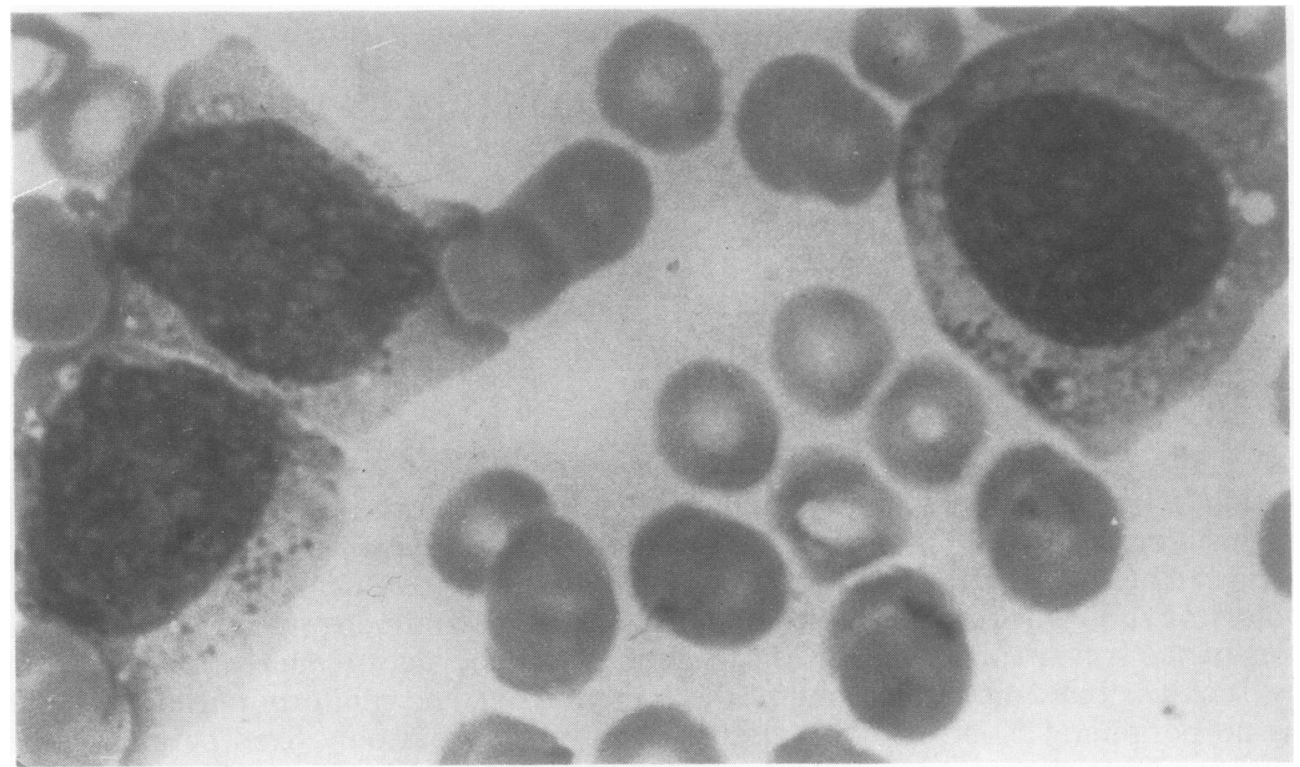

Fig. 1 Monoblasts and promonocytes in the peripheral blood of case 1. May-Grünwald-Giemsa stain $\times$ 1400

ably of the monocytic series. A lymphangiogram showed marked enlargement of inguinal and iliac lymph nodes. A cervical node biopsy (Fig. 2) was reported as showing a malignant lymphoma of lymphoblastic type, but after further investigations (Table) the diagnosis was revised to acute monocytic leukaemia (M5PD). Review of the histological sec- tions showed the malignant cells to have reniform nuclei; they were negative both for chloracetate esterase and for lysozyme (peroxidaseantiperoxidase technique ${ }^{4}$, the occasional neutrophils in the sections being positive for both enzymes. Complete remission occurred after three cycles of combination chemotherapy (cyclophosphamide,

Morphology, cytochemistry and cell markers of leukaemic cells, ${ }^{*}$ and serum lysozyme concentrations

\begin{tabular}{|c|c|c|c|c|c|c|c|}
\hline \multirow[t]{2}{*}{ Case } & \multicolumn{2}{|l|}{ Morphology } & \multicolumn{2}{|l|}{ Cytochemistry } & \multicolumn{2}{|l|}{ Lysozyme } & \multirow{2}{*}{$\begin{array}{l}\text { Other cell } \\
\text { markers }\end{array}$} \\
\hline & $\begin{array}{l}\text { Light } \\
\text { microscopy } \\
(L M)\end{array}$ & $\begin{array}{l}\text { Transmission } \\
\text { electron } \\
\text { microscopy } \\
(T E M)\end{array}$ & $\begin{array}{l}\text { Naphthol-AS- } \\
\text { acetate esterase } \\
\text { (NaF sensitive) }\end{array}$ & $\begin{array}{l}\text { Myeloperoxidase } \\
\text { and/or Sudan } \\
\text { black B }\end{array}$ & $\begin{array}{l}\text { Cytobacterial } \\
\text { test }\end{array}$ & $\begin{array}{l}\text { Serum } \\
\text { concentration } \\
(\mu g / m l) \\
(N R=5-20)\end{array}$ & \\
\hline 1 & $\begin{array}{l}\text { Monoblasts and } \\
\text { promonocytes } \\
\text { (M5PD) }\end{array}$ & ND & ++ & - or + & ++ & $40 \cdot 5$ & $\begin{array}{l}\text { Acid } \\
\text { phosphatase }++\end{array}$ \\
\hline 2 & $\begin{array}{l}\text { Monoblasts and } \\
\text { promonocytes } \\
\text { (M5PD) }\end{array}$ & $\begin{array}{l}\text { Blasts with } \\
\text { small electron- } \\
\text { dense granules } \\
\text { (Fig. 4) }\end{array}$ & + & - or + & ND & ND & $\begin{array}{l}\text { E rosettes } \\
\text { SmIg } \\
\text { cALL } \\
\text { TdT }\end{array}$ \\
\hline 3 & $\begin{array}{l}\text { Monoblasts, } \\
\text { promonocytes } \\
\text { and monocytes } \\
\text { (M5PD) }\end{array}$ & $\begin{array}{l}\text { Blasts with } \\
\text { small electron- } \\
\text { dense granules }\end{array}$ & ++ & $\begin{array}{l}\stackrel{ \pm}{\text { (LM and TEM) }} \\
\text { (Fig. 5) }\end{array}$ & ++ & ND & \\
\hline 4 & $\begin{array}{l}\text { Monoblasts } \\
\text { (M5PD) }\end{array}$ & ND & ++ & - or + & ND & 180 & $\begin{array}{l}\text { Chloracetate } \\
\text { esterase } \\
\text { Acid } \\
\text { phosphatase ++ } \\
\text { PAS - }\end{array}$ \\
\hline
\end{tabular}

*From the blood of all cases, the bone marrow of cases 2 and 4 , and the skin imprints of case 4 using methods previously described. ${ }^{2}$ $\mathrm{ND}=$ not done; $\mathrm{E}$ rosettes = sheep erythrocyte rosette forming cells; $\mathrm{Smlg}=$ surface membrane immunoglobulin; cALL = common $\mathrm{ALL}$ antigen; TdT = terminal deoxynucleotidyl transferase; M5 = monocytic leukaemia (FAB classification); PD = poorly differentiated; NR = normal range. 


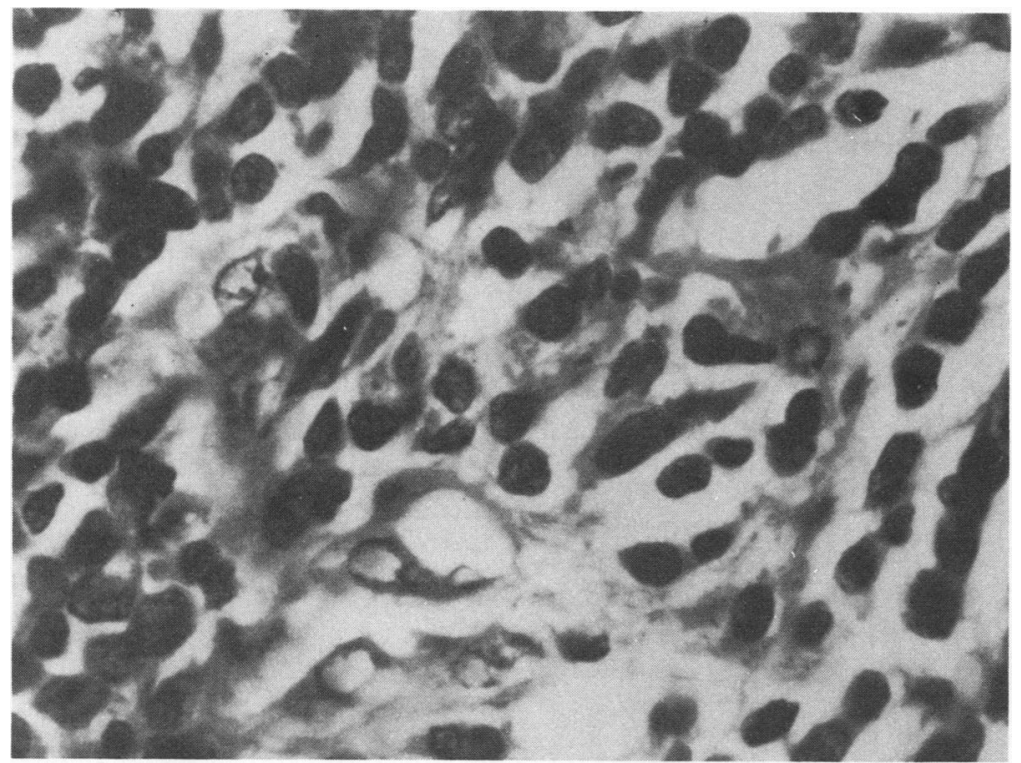

Fig. 2 Histological sections of cervical lymph node of case 2. Haematoxylin and eosin. Original magnification $\times 80$

doxorubicin, vincristine, prednisone). After the sixth cycle relapse occurred with atypical mononuclear cells similar to those at presentation appearing in the peripheral blood, bone marrow and cerebrospinal fluid; they were identified as monoblasts and promonocytes (Figs 3, 4, Table). Two further partial remissions occurred following combination chemotherapy (cytosine arabinoside, thioguanine and VP116), intrathecal chemotherapy and cranial irradiation. Death occurred 22 months from presentation.

\section{CASE 3}

A 40-year-old woman presented with pain in the left shoulder and was found to have left supraclavicular and left axillary lymphadenopathy. A biopsy of a

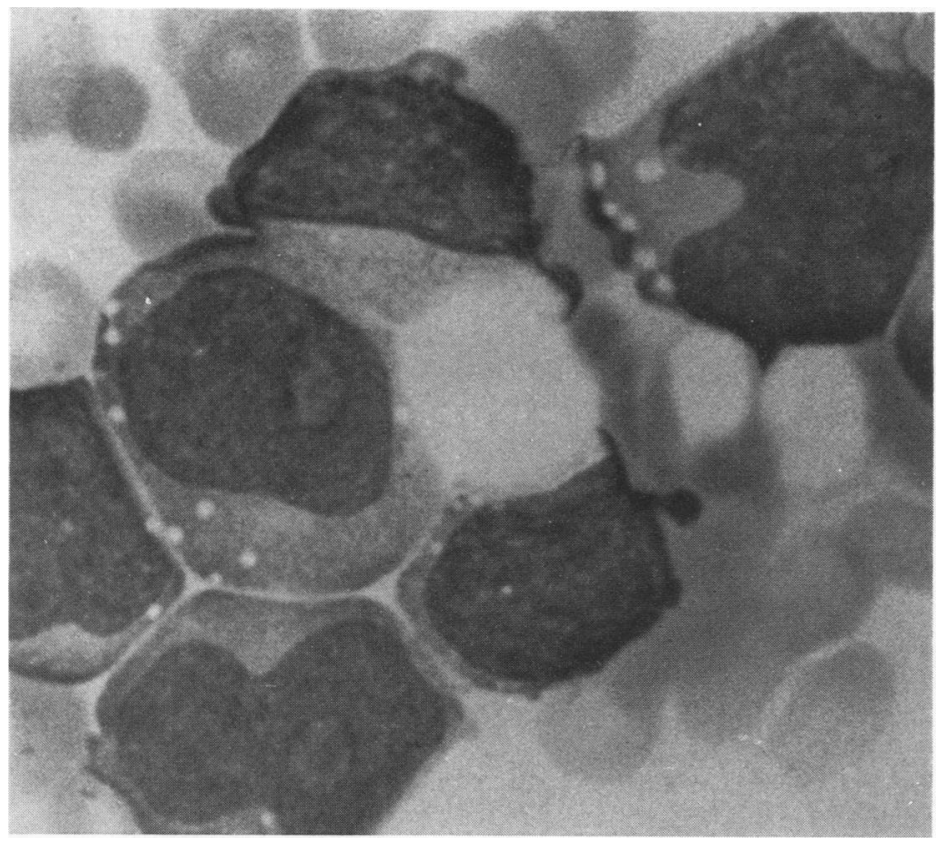

Fig. 3 Poorly differentiated monoblasts in the bone marrow of case 2. May-Grünwald-Giemsa stain $\times 1400$ 
Bain, Manoharan, Lampert, McKenzie, Catovsky $\frac{\varrho}{\overline{5}}$

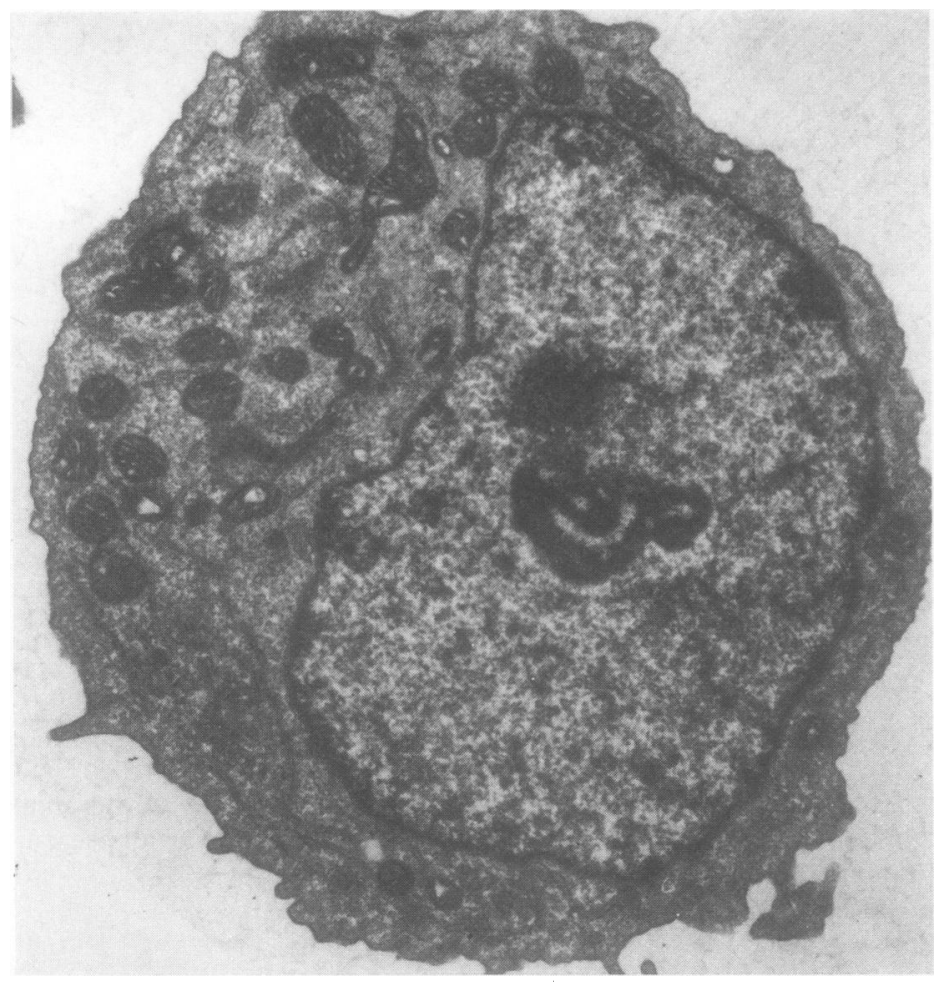

Fig. 4 Electronmicrophotograph of a blast cell of case 2. The cell shows abundant cytoplasm, an active Golgi apparatus, short strands of ER and small electron-dense lysosomal granules. Uranyl acetate and lead citrate stain, $\times 11500$

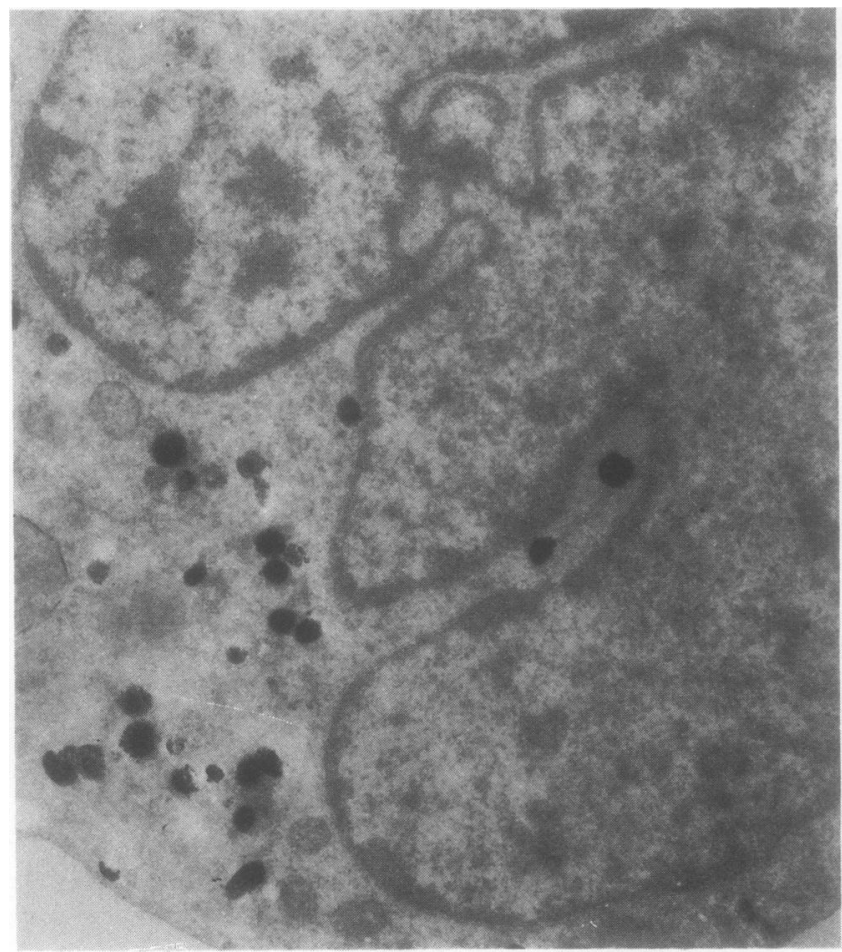

Fig. 5 Electronmicrophotograph of a promonocyte from case 3, showing the positive myeloperoxidase reaction of the cytoplasmic granules. Unstained section $\times 15000$ 
supraclavicular node was reported as showing an anaplastic carcinoma. The peripheral blood was normal and bone marrow aspirate was not done. A good response followed palliative radiotherapy. Four months later relapse occurred with recurrence of lymphadenopathy, subcutaneous nodules (some bluish), a left pleural effusion and an ill defined abdominal mass. The peripheral blood remained normal. A repeat cervical node biopsy was considered consistent with poorly differentiated lymphocytic lymphoma but anaplastic carcinoma was not excluded. After two courses of combination chemotherapy (cyclophosphamide, vincristine, prednisone, procarbazine) there were no abnormal physical findings. Four months later relapse occurred with pleural and pericardial effusions and hepatomegaly. After a further month bluish skin infiltrates appeared and for the first time (12 months from presentation) numerous monoblasts, promonocytes and monocytes were present in the peripheral blood. A diagnosis of acute monocytic leukaemia (M5D) was made (Fig. 5; Table). Rapid clinical deterioration was followed by death. Necropsy showed extensive leukaemia infiltration of bone marrow, lymph nodes, liver, spleen, pericardium, myocardium, pleura and lungs.

\section{CASE 4}

A 36-year-old woman presented with a two-month history of fatigue, weight loss and bone pain. She had subcutaneous scalp nodules, violaceous infiltration of the skin of the chest wall and a palpable left axillary lymph node. The peripheral blood count showed $\mathrm{Hb} 7 \mathrm{~g} / \mathrm{dl}$, WCC $3.3 \times 10^{9} / 1$, neutrophil count $1.3 \times 10^{9} / 1$ and platelet count $200 \times 10^{9} / 1$. Occasional blasts and nucleated red blood cells were present in this blood film but not in a subsequent one. A biopsy of a cutaneous nodule was reported as showing dermal infiltration by "a diffuse lymphoma of mixed small lymphoid and undifferentiated cell type showing high mitotic activity." A difficult bone marrow aspiration yielded a dilute sample with small numbers of both normal haemopoietic cells and large pleomorphic cells interpreted as "malignant cells, probably lymphomatous." The patient was transfused and over the next month there was progression of lymphadenopathy and skin infiltration. By five weeks from presentation there was pancytopenia with $2.8 \times 10^{9} / 1$ blasts in the peripheral blood. Morphology and cytochemistry of cells from the peripheral blood, repeat bone marrow aspirate and skin imprints gave a diagnosis of acute monocytic leukaemia (M5PD) (Table). Review of the skin biopsy confirmed the presence of an infiltrate around skin appendages including the pilar erector muscle. The malignant cells had relatively small reniform nuclei with fine speckled chromatin and insignificant nucleoli. Stains for lysozyme ${ }^{4}$ were positive. Only a partial remission occurred with four courses of daunorubicin, cytosine arabinoside and thioguanine and subsequently VP16-213, vincristine, prednisolone and hydroxyurea. The patient died $5^{1 / 2}$ months after presentation.

\section{Discussion}

Four patients in whom the final diagnosis was acute monocytic leukaemia presented with soft tissue infiltration which was initially interpreted histologically as anaplastic carcinoma (subsequently revised to lymphoma) or lymphoma. Despite the histological difficulty the demonstration of the monocytic nature of the cells was easy on peripheral blood films, and was confirmed by cytochemical and ultrastructural studies (Table). In two patients the peripheral blood and bone marrow were minimally involved at presentation but in the other two such involvement was not detected till two and 12 months from presentation, leading to considerable delay in diagnosis.

The misdiagnosis of granulocytic sarcoma (myeloblastoma) as lymphoma, carcinoma or eosinophilic granuloma is well recognised and quite common, particularly when the granulocytic sarcoma precedes other evidence of acute myeloblastic leukaemia. Of 61 granulocytic sarcomas reviewed by Neiman et al, ${ }^{5} 56 \%$ were misdiagnosed.

A soft tissue tumour presentation appears to be more common in acute monocytic leukaemia (M5) than in acute myeloblastic leukaemia (M1 or M2). Peterson et $a l^{6}$ found that four patients with an extramedullary presentation of acute monocytic leukaemia represented half of their patients with this diagnosis, whereas only $3 \%$ of patients with acute myeloblastic leukaemia presented similarly. Four other patients similar to the ones discussed here (but less completely documented) have been seen at Hammersmith Hospital during the last $10 \mathrm{yr}$, the presenting sites of extramedullary disease being spleen, ovary, mesenteric nodes, and skin. Infiltration of skin, subcutaneous tissues, and lymph nodes is particularly common in acute monocytic leukaemia. The clinical features, including the skin infiltration, may be very similar to those of patients with lymphoma and the distinction must thus be made on histological and cytological grounds. Histological confusion is most likely between monocytic sarcoma and diffuse large cell lymphoma. In the latter condition a leukaemic phase occurs in a minority (less than 10\%) and the cells do not have the distinctive features of monoblasts or promonocytes.

Not only is extramedullary presentation of acute 
monocytic leukaemia more common than such a presentation in acute myeloblastic leukaemia, but diagnosis of a monocytic sarcoma is more difficult than diagnosis of a granulocytic sarcoma. A green tinge on macroscopic inspection may aid in the diagnosis of a granulocytic sarcoma (chloroma) but this coloration, which is due to peroxidase activity, is less likely to be seen in pure monocytic tumours, the peroxidase content of which is low. An admixture with eosinophil myelocytes or chloracetate esterase activity which have been found helpful in the diagnosis of granulocytic sarcoma are not present in pure monocytic tumours. Certain histological features may be helpful. The cellular proliferation is relatively uniform with abundant pale, acidophilic cytoplasm and round to oval nuclei; the nuclear membrane is sharply outlined and the nucleoli are usually small and inconspicuous. The fine, speckled chromatin pattern is suggestive of lymphoblastic lymphoma but some of the nuclei are reniform. In the skin, infiltration is particularly around the appendages but this is also a feature of large cell lymphoma of the skin. In lymph nodes infiltration may be sinusoidal only or may obliterate the node; infiltrating cells are cohesive and phagocytosis is not usually a feature.

In patients without peripheral blood or bone marrow evidence of acute monocytic leukaemia reliance must be placed on (i) cytochemical and other marker techniques applicable to tumour imprints, cryostat sections or tumour cells in suspension; (ii) cytochemical techniques applicable to fixed tissues or (iii) electron microscopy. If imprints are made from lymph nodes or other infiltrated tissues prior to fixation then they may be stained with MayGrünwald-Giemsa stain, and may be used for cytochemical study (for example, the demonstration of fluoride-sensitive naphthol-AS-acetate esterase activity). Cryostat sections may be used for the demonstration of acid phosphatase activity, though this lacks specificity. Tumour cells in suspension or in frozen section may be studied for surface markers and cells will be found to be negative for SmIg and $\mathrm{E}$ rosettes but positive for $\mathrm{Fc}$ receptors; phagocytosis may be demonstrated. ${ }^{7}$ Techniques suitable for use on fixed tissue are of more general applicability. The demonstration of lysozyme by immunohistochemistry using a peroxidase-antiperoxidase technique is often useful, with the advantage that it remains demonstrable in Zenker-fixed and acid-decalcified tissues. Unfortunately lysozyme is not invariably demonstrable in monoblasts, as shown by our second patient and although it is not detected cytochemically in normal myeloblasts it may be shown by immunohistochemistry in granulocytic sarcoma as well as monocytic sarcoma. Immunohistochemistry may also be used to demonstrate alpha-1-antitrypsin $\left(\alpha_{1} \mathrm{AT}\right)$ and peanut agglutinin ${ }^{8} 9$ in fixed tissues. $\alpha_{1} \mathrm{AT}$ is present in cells of the monocyte-macrophage lineage, but does not appear to have any advantage over lysozyme for detection $\stackrel{?}{?}$ of immature cells of this lineage. ${ }^{8}$ The demonstra- $\bar{C}$ tion of peanut agglutinin appears to be a more sensi- $\frac{\bar{O}}{\vec{D}}$ tive technique than the demonstration of lysozyme $\frac{\bar{\omega}}{\vec{D}}$ for the detection of macrophages but its usefulness $\stackrel{\mathbb{D}}{\triangle}$ to detect monoblasts has not yet been shown. ${ }^{9}$ A recently described modification of paraffin- $\vec{D}$ embedding techniques ${ }^{10}$ allows a wider range of histochemical studies (including acid phosphatase and $\vec{\omega}$ alpha-naphthyl-acetate esterase) on routine his- $\stackrel{\circ}{\circ}$ tological specimens: if this technique proves gener- 용 ally applicable the correct diagnosis of monocytic $\dot{\omega}$ tumours should be facilitated. The demonstration of $i$ cytoplasmic granules on electron microscopy may be $i$ the first indication that a tumour is of myeloblastic 0 or monocytic origin rather than lymphoid. ${ }^{11}$ Ultra- $\frac{\text { O }}{2}$ structural cytochemistry (acid phosphatase and peroxidase $^{12}$ may also be helpful, as shown in our third patient).

Raised serum or urinary lysozyme concentrations $\vec{\varphi}$ are useful in confirming a diagnosis of monocytic sarcoma, but they are not invariably found.

Acute monoblastic leukaemia may present with no extramedullary involvement, with both medullary and extramedullary disease, or with extramedullary tumour with the later evolution to leukaemia. $\frac{\mathrm{D}}{\mathrm{O}}$ Correct diagnosis may be particularly important in the third group. It is not known whether in such 을 patients the origin of the leukaemic clone is in the bone marrow with early seeding to extramedullary sites, or whether its origin is extramedullary with haematogenous spread to bone marrrow and other sites. If the latter is the case then it might be possible $\dot{0}$ to harvest and cryopreserve bone marrow prior to 3 systemic chemotherapy in those patients who have $\delta$ no evidence of marrow involvement at presentation. In either case the recognition of the cell line 0 involved indicates the need for intensive systemic therapy rather than local therapy (eg radiotherapy) for successful treatment of this disease. Correct diagnosis is also important to avoid misinterpreta- $\sigma$ tion of acute monocytic leukaemia as a therapy- $N$ related leukaemia following successful treatment of $\underset{\mathrm{W}}{\mathrm{N}}$ a lymphoma. It may be justifiable to regard a soft 0 tissue monocytic sarcoma as a "true histiocytic lymphoma" but it should then be recognised that a sub- $\frac{\bar{\Phi}}{\Phi}$ sequent acute monocytic leukaemia is another phase $\stackrel{?}{?}$ of the same malignant proliferation and not a second 0 malignancy. This tumour should not be confused with the larger group of "histiocytic" lymphomas of $\stackrel{\mathbb{D}}{\mathbb{D}}$ Rappaport's classification. ${ }^{1}$ The majority of such $\frac{\mathbb{D}}{\mathrm{D}}$ tumours can now be identified as being of $T$ or $B \stackrel{2}{\circ}$ lymphocyte origin, although a significant proportion 
of the non-B, non-T (null) lymphomas are of true histiocytic origin. ${ }^{7}$ Since the monocyte and the histiocyte belong to the same cell line a monocytic sarcoma and a true histiocytic lymphoma may be regarded as variants of the same tumour type. The former designation emphasises that this tumour is part of the spectrum of acute monocytic leukaemia whereas the latter name suggests histological similarities to lymphomas of true lymphoid origin. The relation to acute monocytic leukaemia is further emphasised by the natural history of the disease which almost always terminates in frank monocytic leukaemia.

\section{References}

${ }^{1}$ Rappaport H. Tumours of the hematopoietic system. Atlas of tumour pathology Section 3, Fascicle 8. Washington DC: Armed Forces Institute of Pathology, 1966.

${ }^{2}$ Catovsky D, Cardullo L de S, O'Brien M, et al. Cytochemical markers of differentiation in acute leukaemia. Cancer Res 1981;41:4824-32.

${ }^{3}$ Bennet JM, Catovsky D, Daniel MT, et al. Proposals for the classification of the acute leukaemias (FAB Co-operative Group). Br J Haematol 1976;33:451-8.
${ }^{4}$ Mason DY, Taylor CR. The distribution of muramidase (lysozyme) in human tissues. J Clin Pathol 1975;28:124-32.

5 Neiman RS, Barcos M, Berard C, et al. Granulocytic sarcoma: a clinicopathological study of 61 biopsied cases. Cancer 1981;48:1426-37.

6 Peterson L, Dehner LP, Brunning RD. Extramedullary masses as presenting features of acute monoblastic leukaemia. Am J Clin Pathol 1981;75:140-48.

${ }^{7}$ Habeshaw AJ. Surface phenotypes of large-cell lymphoma. Br J Cancer 1981;44:926-8.

- Isaacson P, Wright DH, Judd MA, Mepham BL. Primary gastrointestinal lymphomas. Cancer 1979;43:1805-19.

' Howard DR, Batsakis JG. Peanut agglutinin: a new marker for tissue histiocytes. Am J Clin Pathol 1982;77:401-8.

${ }^{10}$ Chilosi M, Pizzolo G, Menestrina F, Iannuca AM, Bonetti F, Fiore-Donati L. Enzyme histochemistry on normal and pathological paraffin-embedded lymphoid tissues. Am J Clin Pathol 1981;76:729-36.

"Strauss DJ, Mertelsmann R, Koziner B, et al. The acute monocytic leukaemias: multidisciplinary studies in 45 patients. Medicine 1980;59:409-25

${ }^{12}$ O'Brien M, Catovsky D, Costello C. Ultrastructural cytochemistry of leukaemic cells: characterisation of the early small granules of monoblasts. Br J Haematol 1980;45:201-8.

Requests for reprints to: Dr D Catovsky, MRC Leukaemia Unit, Royal Postgraduate Medical School, Hammersmith Hospital, Ducane Road, London W12 0HS, England. 